\title{
BMJ Open HIV/AIDS mortality attributable to alcohol use in South Africa: a comparative risk assessment by socioeconomic status
}

\author{
Charlotte Probst, ${ }^{1,2}$ Charles D H Parry, ${ }^{3,4}$ Jürgen Rehm ${ }^{1,2,5,6,7}$
}

To cite: Probst C, Parry CDH, Rehm J. HIV/AIDS mortality attributable to alcohol use in South Africa: a comparative risk assessment by socioeconomic status. BMJ Open 2018:8:e017955. doi:10.1136/ bmjopen-2017-017955

- Prepublication history and additional material for this paper are available online. To view these files, please visit the journal online (http://dx.doi. org/10.1136/bmjopen-2017017955).

Received 31 May 2017 Revised 27 December 2017 Accepted 3 January 2018

Check for updates

For numbered affiliations see end of article.

Correspondence to Charlotte Probst; mariecharlotte.probst@gmail. com

\section{ABSTRACT}

Objectives To quantify HIV/AIDS mortality attributable to alcohol use in the adult general population of South Africa in 2012 by socioeconomic status (SES).

Design Comparative risk assessment based on secondary individual data, aggregate data and risk relations reported in the literature.

Setting South African adult general population. Participants For metrics of alcohol use by SES, sex and age: 27070 adults that participated in a nationally representative survey in 2012. For HRs of dying from HIV/AIDS by SES: 87029 adults that participated in a cohort study (years 2000 to 2014) based out of the Umkhanyakude district, KwaZulu-Natal.

Main outcome measures Alcohol-attributable fractions for HIV/AIDS mortality by SES, age and sex were calculated based on the risk of engaging in condom-unprotected sex under the influence of alcohol and interactions between SES and alcohol use. Age-standardised HIV/AIDS mortality rates attributable to alcohol by SES and sex were estimated using alcohol-attributable fractions and SES-specific and sexspecific death counts. Rate ratios were calculated comparing age-standardised rates in low versus high SES by sex.

Results The age-standardised HIV/AIDS mortality rate attributable to alcohol was 31.0 (95\% uncertainty interval (UI) 21.6 to 41.3 ) and 229.6 (95\% UI 108.8 to 351.6 ) deaths per 100000 adults for men of high and low SES, respectively. For women the respective rates were 10.8 (95\% UI 5.5 to 16.1 ) and 75.5 (95\% UI 31.2 to 144.9$)$. The rate ratio was 7.4 (95\% UI 3.4 to 13.2$)$ for men and 7.0 (95\% UI 2.8 to 18.2) for women. Sensitivity analyses corroborated marked differences in alcohol-attributable HIV/AIDS mortality, with rate ratios between 2.7 (95\% UI 0.8 to 7.6 ; women) and 15.1 (95\% UI 6.8 to 27.7 ; men). Conclusions The present study showed that alcohol use contributed considerably to the socioeconomic differences in HIV/AIDS mortality. Targeting HIV infection under the influence of alcohol is a promising strategy for interventions to reduce the HIV/AIDS burden and related socioeconomic differences in South Africa.

\section{INTRODUCTION}

HIV/AIDS was the disease with the highest health burden in South Africa in 2016, accounting for over $30 \%$ of the total burden of disease. ${ }^{1}$ Research showed that the HIV/AIDS

\section{Strengths and limitations of this study}

- This study on the alcohol-attributable HIV/AIDS mortality in South Africa is unique in quantifying the disparities between different socioeconomic groups.

- A comparative risk assessment was performed using individual data, aggregate data and relative risk relations reported in the literature.

- Due to limitations in the available data, this study had to apply a coarse split in two major socioeconomic groups.

- Given a likely under-reporting of alcohol use in nationally representative South African surveys, it is possible that the prevalence of current alcohol use was underestimated, while the average gram per day among current drinkers and thereby the respective alcohol-attributable fractions were overestimated in the current study.

burden in South Africa was unequally distributed across different levels of socioeconomic status (SES). Persons of low SES were shown to have a higher HIV prevalence, ${ }^{2}$ and an at least 1.5 times higher risk of dying from HIV/AIDS compared with persons of high SES. ${ }^{3}$ With a Gini index over 60, South Africa is among the countries worldwide where income is most unequally distributed. ${ }^{4}$ Not least due to the history of colonialism and apartheid, socioeconomic differences in South Africa are heavily intertwined with race and despite decreasing trends, the average income of a white person is still over 10 times that of a black African person. ${ }^{5}$

One factor possibly contributing to the socioeconomic differences in HIV/AIDS burden is alcohol use. While in South Africa and elsewhere, current drinkers of low SES were shown to drink higher quantities and in overall riskier patterns, they were-partly due to lower affordability of alcohol-also more likely to abstain from alcohol completely. ${ }^{6-9}$ A study based on nationally representative data from South Africa recently found an 


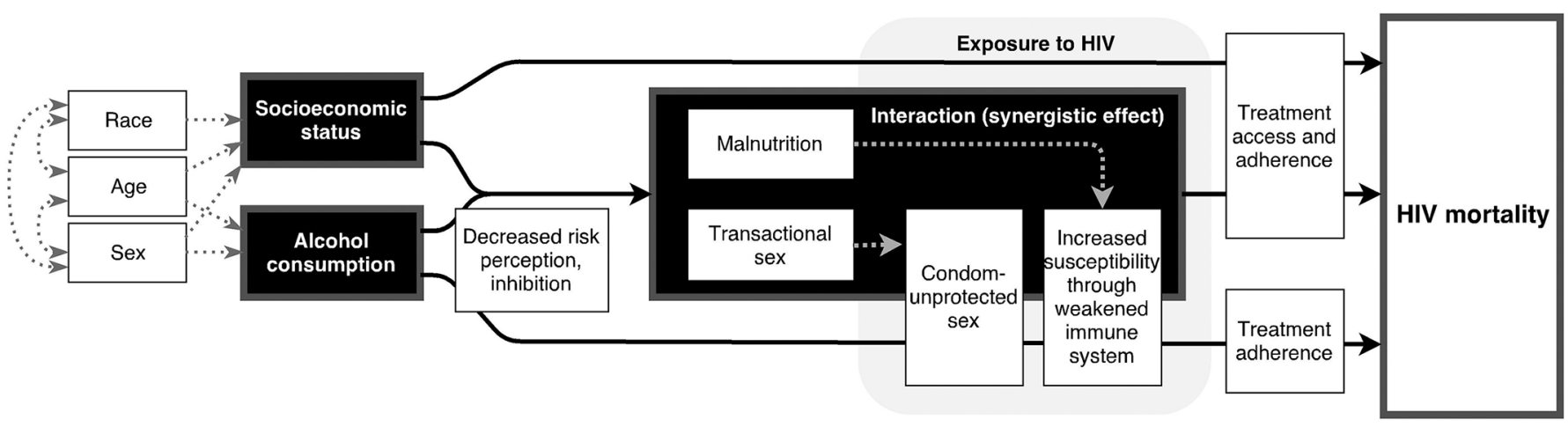

Figure 1 Conceptual framework linking alcohol use and socioeconomic status to HIV/AIDS mortality.

interaction between SES and alcohol use on HIV infection risk, indicating that persons of low SES increase their risk of contracting HIV significantly more when drinking alcohol compared with their counterparts of high SES. ${ }^{10}$

Alcohol is a psychotropic depressant of the central nervous system that likely impairs decision-making by diminishing the perception of risk and reducing inhibitions. ${ }^{11}$ Particularly occasional heavy drinking has been linked to sexual risk behaviour and an increased HIV infection risk in cross-sectional and longitudinal studies from Sub-Saharan Africa as well as other countries. ${ }^{12-16}$ A series of randomised experiments corroborated the findings by showing that (HIV-positive) participants were significantly more likely to consider condom-unprotected sex when under the influence of alcohol. ${ }^{17}$ Overall, the evidence supports causal effects of alcohol use on HIV infection risk. ${ }^{18}$ Interactive effects of alcohol use and SES could be the result of a number of contextual factors such as the drinking environment, malnutrition and poverty that work to the disadvantage of persons of low SES. ${ }^{10}$ As a consequence, alcohol use is likely to contribute to socioeconomic differences in HIV/AIDS mortality in South Africa above and beyond potential differences in the drinking patterns.

Figure 1 shows a conceptual framework of the associations between alcohol use, SES and HIV/AIDS mortality. The focus of the current study was on alcohol use as a risk factor for HIV infection via condom-unprotected sex. ${ }^{19-22}$ Interactions between alcohol use and a low SES, ${ }^{10}$ likely due to interactions between alcohol use and malnutrition, ${ }^{23}$ were taken into account. Effects of alcohol use on the mortality risk after HIV infection (eg, through delayed treatment initiation, reduced treatment adherence and increased risk of opportunistic infections ${ }^{2526}$ ) were not modelled in the current study. Previous research showed that less than $0.5 \%$ of HIV/AIDS deaths could be explained through non-adherence to antiretroviral therapy due to alcohol use in Sub-Saharan Africa.

Even though there is worldwide a large body of evidence showing increased risk of all-cause and alcohol-attributable mortality for persons of low SES, there have been few attempts to incorporate SES in burden of disease estimations. ${ }^{27} 28$ The objective of the current study was to quantify the burden of HIV/AIDS mortality attributable to alcohol use by SES, age and sex in South Africa in 2012.

\section{METHODS}

A comparative risk assessment was performed to estimate alcohol-attributable HIV/AIDS mortality for different subgroups defined by SES, age and sex. The methodology was based on previous burden of disease and mortality analyses. $^{29-31}$

Figure 2 gives a schematic overview of the procedures and data sources. In step 1, alcohol-attributable fractions (AAFs) were calculated, representing the proportion of HIV/AIDS deaths that would not have occurred under the counter-factual scenario that everyone would have been a lifetime abstainer. To calculate the AAF, information on exposure to alcohol in each subgroup was combined with the risk associated with the level of exposure in the particular subgroup (see formula 1 in the online supplementary material).

In the second step, the AAF of each subgroup was applied to the HIV/AIDS deaths in the subgroup to calculate the alcohol-attributable deaths. This required knowledge on the HIV/AIDS death counts in each subgroup (see section 'Mortality'). In the third step, the alcohol-attributable deaths were combined with population counts to calculate HIV/AIDS mortality rates per 100000 adults. The mortality rates were age-standardised using the WHO reference population. ${ }^{32}$ Mortality rate ratios were obtained by dividing the age-standardised mortality rate in the low SES group by the one in the high SES group.

The following paragraph will define the core measures used in the comparative risk assessment and provide details on the four areas shown in figure 2, namely alcohol exposure, risk, mortality and population. If not indicated differently, all analyses were performed in R V.3.2.3. The analyses conformed to the principles embodied in the Declaration of Helsinki, and ethics approval was obtained from the Centre for Addiction and Mental Health Research Ethics Board. 
Alcohol-attributable HIV/AIDS mortality

\begin{tabular}{|c|c|c|c|c|c|}
\hline $\begin{array}{l}\overline{0} \\
\frac{0}{0} \\
\frac{8}{\pi} \\
0\end{array}$ & $\begin{array}{l}\text { Prevalence of alcohol use } \\
\text { and grams per day by } \\
\text { subgroup in } 2012 \\
\text { [individual data: SABSSM] }\end{array}$ & \multirow{2}{*}{$\begin{array}{l}\text { Exposure to } \\
\text { alcohol use by } \\
\text { subgroup } \\
\text { corrected for } \\
\text { underestimation } \\
\text { [method: } \\
\text { Kehoe et al., } \\
2012 \text { ] }\end{array}$} & \multirow[t]{6}{*}{$\begin{array}{l}\text { Alcohol- } \\
\text { attributable } \\
\text { fractions by } \\
\text { subgroup }\end{array}$} & \multirow[t]{5}{*}{$\begin{array}{l}\text { Alcohol- } \\
\text { attributable } \\
\text { HIV/AIDS deaths } \\
\text { by subgroup }\end{array}$} & \multirow{6}{*}{$\begin{array}{l}\text { Alcohol- } \\
\text { attributable } \\
\text { HIV/AIDS } \\
\text { mortality rates in } \\
\text { each subgroup } \\
\text { Age-standardized } \\
\text { alcohol- } \\
\text { attributable } \\
\text { HIV/AIDS } \\
\text { mortality rates by } \\
\text { SES and sex } \\
\text { [Ahmad et al. } \\
\text { 2001] } \\
\text { Age-standardized } \\
\text { mortality rate } \\
\text { ratios of alcohol- } \\
\text { attributable } \\
\text { HIV/AIDS } \\
\text { mortality }\end{array}$} \\
\hline 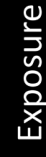 & $\begin{array}{l}\text { Total adult per capita } \\
\text { alcohol consumption in to } \\
\text { total population in } 2012 \\
\text { [aggregate data: GISAH] }\end{array}$ & & & & \\
\hline & $\begin{array}{l}\text { Interaction between SES an } \\
\text { risk [evidence: Probst et al. }\end{array}$ & $\begin{array}{l}\text { d alcohol use for HIV } \\
\text { 2017] }\end{array}$ & & & \\
\hline & $\begin{array}{l}\text { Relative risk of acquiring } \mathrm{HI} \\
\text { sex under influence of alco } \\
\text { [evidence: Scott-Sheldon et }\end{array}$ & $\begin{array}{l}\text { V through unprotected } \\
\text { hol vs. abstinence } \\
\text { al., 2016] }\end{array}$ & & & \\
\hline & $\begin{array}{l}\text { Number of HIV/AIDS } \\
\text { deaths in South Africa in } \\
2012 \text { by sex and age } \\
\text { [aggregate data: WHO] }\end{array}$ & $\begin{array}{l}\text { Relative risk to split } \\
\text { HIV/AIDS deaths by } \\
\text { SES } \\
\text { [evidence: Probst et } \\
\text { al. 2016; data: DSA] }\end{array}$ & & & \\
\hline$\frac{\text { 을 }}{\frac{\pi}{5}}$ & \multicolumn{2}{|c|}{$\begin{array}{l}\text { Population counts in each subgroup in } 2012 \\
\text { [individual data: SABSSM] } \\
\text { [aggregate data: Statistics South Africa] }\end{array}$} & & & \\
\hline
\end{tabular}

Figure 2 Schematic overview of the data sources, relative risks and core data processing steps used to quantify alcohol-attributable HIV/AIDS mortality by SES in South Africa for the year 2012. A subgroup was defined by SES, age and sex. HIV risk is referring to HIV acquired through condom-unprotected sex under the influence of alcohol. Sources: Probst et $\left.a\right|^{3}$, Probst et $a^{10}$, Scott-Sheldon et a $l^{17}$, Ahmad et $a /^{32}$, Shisana et al ${ }^{33}$, Kehoe et a $\left.\right|^{36}$, Statistics South Africa ${ }^{44}$. AAF, alcohol-attributable fraction; GISHA, Global Information System on Alcohol and Health; SABSSM, South African National HIV Prevalence, Incidence and Behaviour Survey; SES, socioeconomic status.

\section{Definition of core measures}

The analyses refer to the adult general population defined as 15 years of age or older. A subgroup was defined by SES (high or low), sex (male or female) and age category (15 to 34,35 to 54 and 55 years and older). SES was operationalised as an asset score splitting the population at the median into two equal halves. Alcohol use was categorised into current abstainers (no alcohol use in the past 12 months) and current drinkers. Average grams of pure alcohol per day were calculated among current drinkers.

\section{Exposure to alcohol}

The prevalence of current abstinence and current alcohol use, as well as the average grams of pure alcohol per day in each subgroup, were calculated based on nationally representative survey data. Secondary data from the nationally representative South African National HIV Prevalence, Incidence and Behaviour Survey (SABSSM) from the year 2012 were used. ${ }^{33}$ In SABSSM, households were sampled based on a multistage sampling frame, excluding homeless and institutionalised persons. A total of 27070 adults were interviewed by trained field workers.
Household assets such as television ownership or type of water supply were recorded. The frequency of alcohol use was assessed with the question 'How often did you have a drink containing alcohol in the past 12 months?', with response categories ranging from 'Not in the past 12 months' to ' 4 or more times a week'. The quantity was assessed as 'How many drinks containing alcohol do you have on a typical day when you are drinking?', with response categories ranging from ' 1 or 2' to ' 10 or more'. The frequency of irregular heavy drinking occasions with four/five (for women/for men) drinks or more was assessed in categories ranging from 'never' to 'daily or almost daily'. Based on these variables, the grams of pure alcohol per day among current drinkers in each subgroup were calculated. A standard drink was defined as $12 \mathrm{~g}$ of pure alcohol. All calculations were performed using survey weights. More details on SABSSM are provided in the online supplementary data.

The assessment of population-level alcohol use in surveys is associated with under-reporting and exclusion of population groups with potentially high levels of 


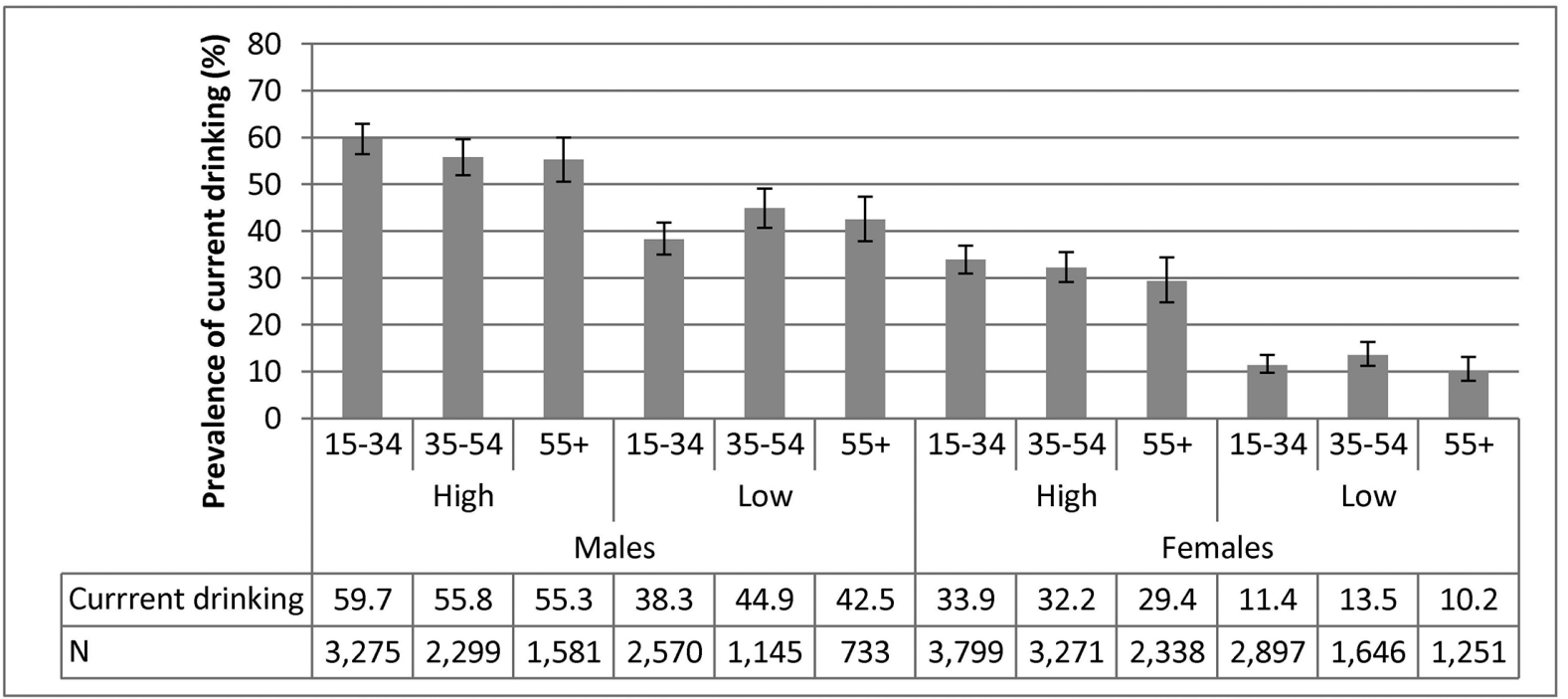

Figure 3 Prevalence of current drinking and sample size by subgroup based on the South African National HIV Prevalence, Incidence and Behaviour Survey, 2012.

alcohol use, leading to an underestimation of the 'true' amount of alcohol consumed. ${ }^{3435}$ The standard triangulation technique of the Global Burden of Disease study and WHO Global Status Reports was applied to correct for underestimation. ${ }^{36} 37$ The consumption in the subgroups was thereby shifted up to match in sum $80 \%$ of the total per capita alcohol consumption in 2012. The aggregate total adult per capita consumption in litres of pure alcohol was obtained from the WHO Global Information System on Alcohol and Health. ${ }^{38}$ A total of $10.39 \mathrm{~L}$ of pure alcohol were consumed per capita in South Africa in 2012.

\section{Alcohol-related risk}

The risk relating different levels of alcohol use to HIV/AIDS was derived from two main sources. An OR from a meta-analysis (including 28 experimental studies predominantly from North America and the UK) performed by Scott-Sheldon $e t a l^{17}$ was used. The OR of 1.54 (95\% CI 1.31 to 1.78 ) referred to intentions to engage in condom-unprotected sex under the influence of alcohol use compared with current abstinence. Specifically, the OR referred to a minimum of 61 and $49 \mathrm{~g}$ per drinking occasion among men and women, respectively (see also online supplementary material). A detailed discussion on the use of the above OR in comparative risk assessments of HIV/AIDS mortality can be found elsewhere. ${ }^{18}$ Since this OR was lower than those reported in observational cohort studies from Sub-Saharan African countries, ${ }^{14} 39$ it can be considered as conservative; in addition, it captured only the causal effect of alcohol as it was based exclusively on experimental studies.

Furthermore, a recent study using three cross-sectional representative surveys from South Africa in the years 2005, 2008 and 2012 showed that alcohol use and SES interact to increase the risk of testing HIV positive among current drinkers of low SES. ${ }^{10}$ The OR (interaction term) of 1.94 (95\% CI 1.29 to 2.93) from the year 2012 was used to account for the increased risk of current drinkers of low SES.

\section{Mortality}

Aggregate HIV/AIDS death counts in 2012 by age group and sex were obtained from WHO. To obtain death counts in each subgroup, that is, split by SES, a relative risk of dying from HIV/AIDS for people of low compared with high SES was used.

South African cohort studies that reported a relative risk of dying from HIV/AIDS by SES, based on an asset score, were identified through a recently published systematic review and recalculated to comply with the operationalisation of SES used in the current study. ${ }^{3}$ In the case of the Agincourt health and sociodemographic surveillance system, Houle et al were asked to recalculate the results accordingly. ${ }^{40}$ In the case of the Demographic Surveillance Area (DSA), original data were used to recalculate the respective $\mathrm{HR}^{41}{ }^{42}$ as described below. Both measures of relative risk were combined in a random-effects meta-analysis, performed in Stata V.13 (see online supplementary material).

The secondary cohort data were obtained from the DSA of the Africa Centre for Health and Population Studies. ${ }^{412}$ The study was based in a predominantly rural area in the Umkhanyakude district of KwaZulu-Natal, comprising also periurban informal settlements and a township. An open cohort of about 11000 households was surveyed between 2000 and 2014. Each household was visited at least two to three times a year. Trained field workers assessed household demographic and socioeconomic information in face-to-face interviews. Cause of death was determined using verbal autopsy interviews with the next of kin. ${ }^{43}$ The sample used in this study comprised 87029 adults, 757404 person-years (average 
15-34 years

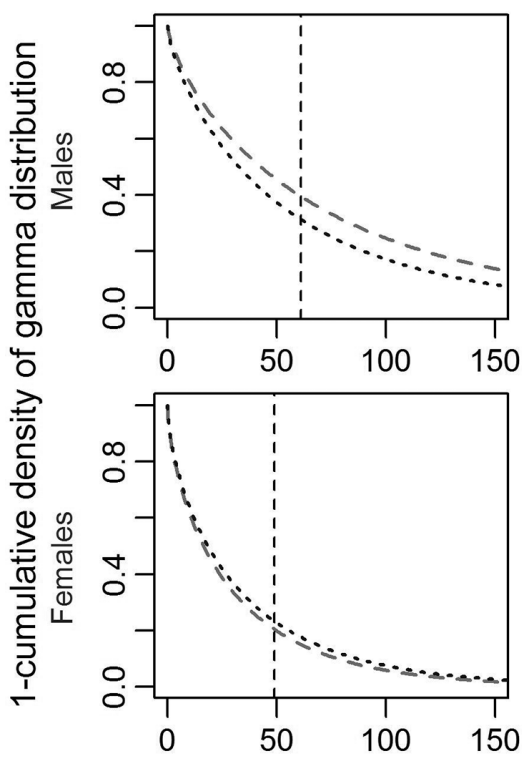

$35-54$ years
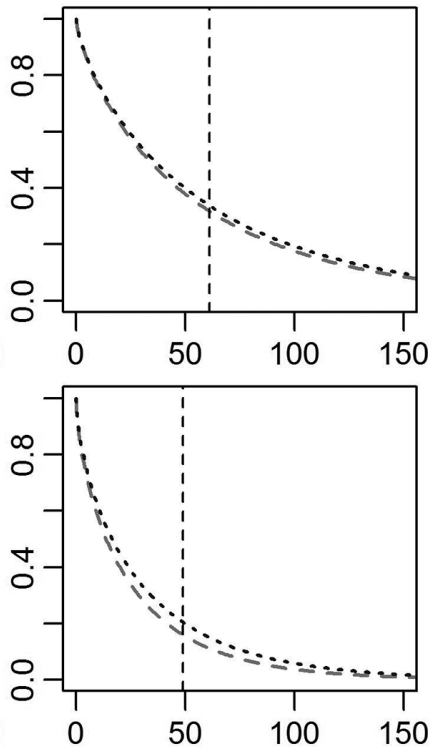

$55+$ years
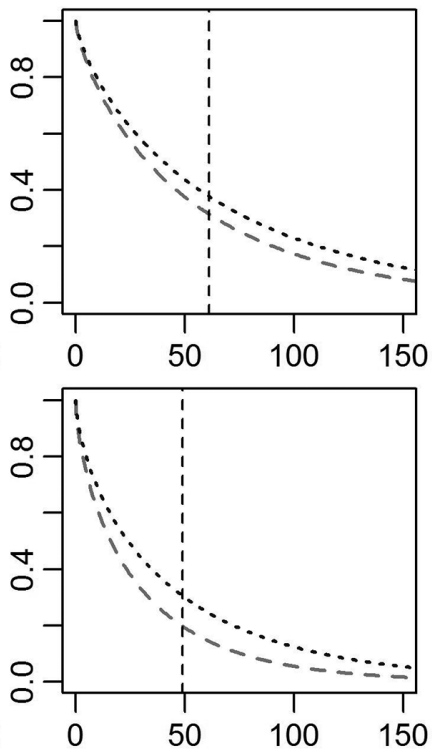

Grams of alcohol per day

Figure 4 One minus the cumulative density of the gamma distribution of alcohol use for high (dashed) and low SES (dotted) and by age and sex in the adult (15+) South African general population in 2012. The graph indicates the proportion of current drinkers (y-axis) with an average level of drinking of alcohol use equal to or above the grams of pure alcohol per day indicated on the $\mathrm{x}$-axis.

follow-up time was 8.7 years) and 5212 deaths from HIV/AIDS. Cox proportional hazards survival analyses were performed using the DSA data. The HR of dying from HIV/AIDS was calculated for the median split and for a mapped asset score, adjusting for age and sex. Kaplan-Meier Survival Curves are shown in online supplementary material.

\section{Population}

Aggregate population counts were based on 2011 census information. ${ }^{44}$ To calculate counts in each subgroup, proportions observed in SABSSM data were applied. Population counts were used as denominators to calculate mortality rates per 100000 adults.

\section{Calculate asset scores}

An asset score was calculated for SABSSM as well as DSA data using Multiple Correspondence Analysis (MCA; eg, from South Africa see Wabiri and $\mathrm{Taffa}^{2}$ ). In a first step, all variables for which $95 \%$ of all participants gave the same answer were excluded to assure stability of the model. Then missing values in individual asset variables were imputed based on an iterative MCA algorithm, using the imputeMCA command from the missMCA package in $\mathrm{R} .{ }^{45}$ After fitting the MCA on the imputed data, variables for which all categories contributed less than $1.5 \%$ to the first dimension were excluded. The asset score was calculated as a median split of the first dimension resulting from the MCA. This resulted in two socioeconomic groups representing the lower and the upper $50 \%$ of the socioeconomic distribution in the adult population. A second version of the asset score of the DSA was calculated to correct for the predominantly rural and lower SES population of the study area. The continuous asset score (first dimension) was mapped on to the continuous asset score of the nationally representative SABSSM data and split at the percentile corresponding to the median of the national distribution.

Race groups were highly unequally distributed across the two levels of SES with $98 \%$ of all whites being in the upper SES group and $97 \%$ of all persons in the low SES group being black African (SABSSM data). Detailed information on the asset scores and associations with race are shown in the online supplementary material.

\section{Uncertainty estimation}

Uncertainty of all calculated metrics (ie, AAFs, mortality rates and mortality rate ratio) was determined using Monte Carlo simulations, ${ }^{46}$ sampling from the distribution of each parameter 100000 times. The 95\% uncertainty interval (UI) was estimated using the 2.5th and 97.5 th percentile of the distribution of the sampled metric.

\section{Sensitivity analyses}

Two sensitivity analyses were performed to examine the stability of the results under different assumptions. Sensitivity analysis I used the mapped asset score instead of the median split asset score. Sensitivity analysis II was performed applying the interaction term exclusively for current alcohol use above the critical 


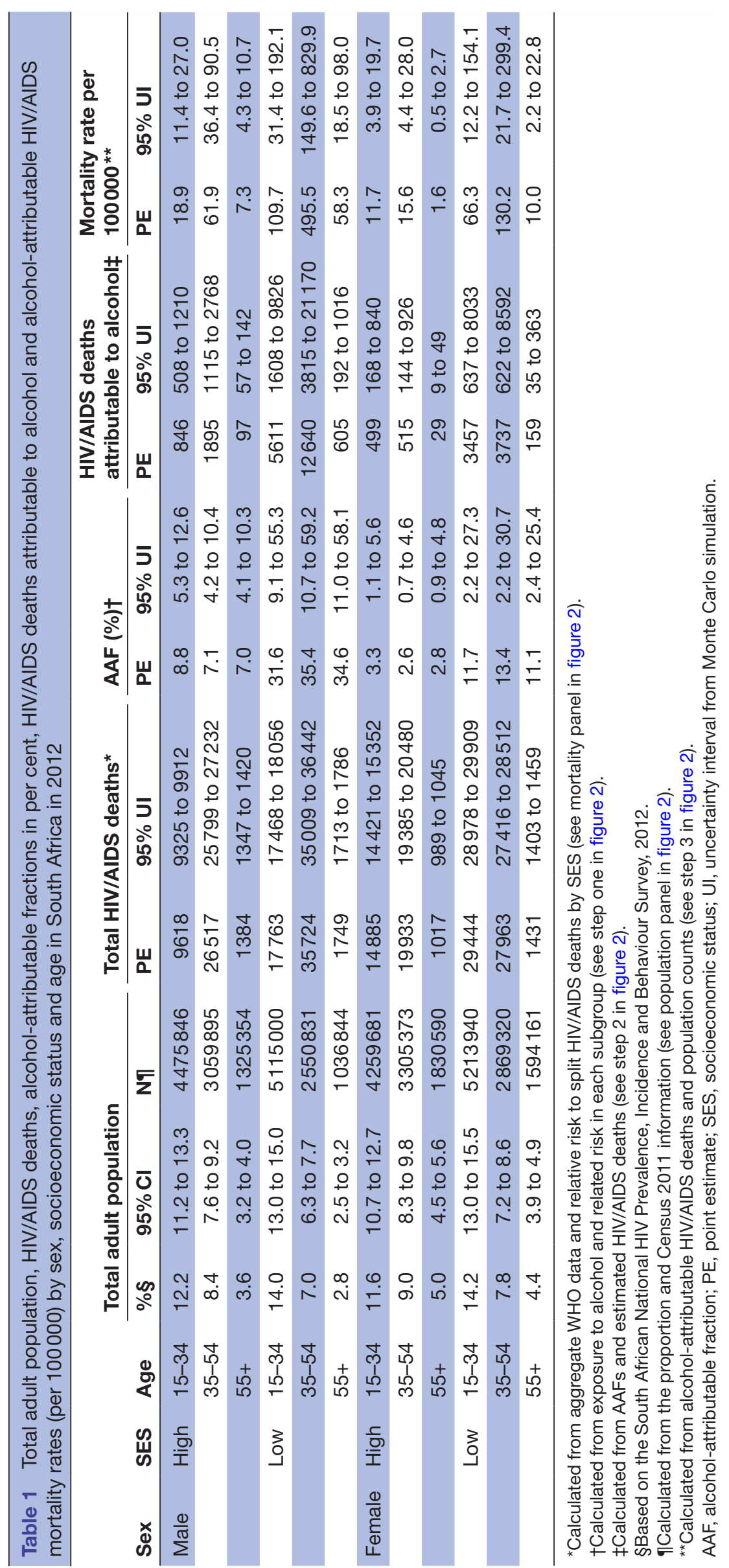


thresholds described in the 'Alcohol-related risk' section.

\section{RESULTS}

\section{Alcohol use}

Results on alcohol use based on SABSSM data are shown in figure 3. Across age groups and sex, the prevalence of current drinking was higher at high compared with low SES.

Figure 4 shows the distribution (one minus the cumulative gamma density distribution) of alcohol use in each subgroup that has been corrected for under-reporting. At each level of alcohol use measured in average grams of pure alcohol per day, the graph indicates the proportion of current drinkers that drank at this level or above it. With the only exception of young men, the proportion of current drinkers above the threshold of 49/61 $\mathrm{g}$ of pure alcohol per day was greater in the low than in the high SES group.

\section{Mortality}

The survival analysis using DSA data resulted in an HR of 1.60 (95\% CI 1.51 to 1.70 ) for persons of low compared with high SES, adjusting for sex and age at baseline. The recalculated relative risk from Houle $e t a l^{40}$ was $1.65(95 \%$ CI 1.52 to 1.78) for persons of low compared with high SES, adjusting for sex and age at baseline. Combining both using a random-effects meta-analysis resulted in a relative risk of dying from HIV/AIDS at low compared with high SES of 1.62 (95\% CI 1.54 to 1.96). HIV/AIDS deaths in each subgroup are shown in table 1 . The HR based on the mapped asset score, used in sensitivity analysis I, was 3.30 (95\% CI 2.82 to 3.87 ).

\section{Comparative risk assessment}

AAFs showed that while in women of high SES, roughly $3 \%$ of all HIV/AIDS deaths were attributable to alcohol; among women of low SES, this was the case for just over $10 \%$ (table 1). Similarly, among men of high SES, $7 \%$ to 9\% of all HIV/AIDS deaths were alcohol attributable, while over $30 \%$ of the HIV/AIDS death in men of low SES was alcohol attributable. In 2012, approximately 30000 HIV/AIDS deaths among adults were attributable to alcohol in South Africa, about 26000 of which appeared in persons of low SES.

Among women, the age-standardised mortality rates for HIV/AIDS mortality attributable to alcohol were 10.8 (95\% UI 5.5 to 16.1 ) per 100000 and 75.5 (95\% UI 31.2 to 144.9 ) per 100000 at high and low SES, respectively. The age-standardised mortality rates among men were 31.0 (95\% UI 21.6 to 41.3) per 100000 in men of high and 229.6 (95\% UI 108.8 to 351.6) per 100000 in men of low SES.

The ratio comparing age-standardised rates of alcohol-attributable HIV/AIDS mortality in high versus low SES was 7.4 (95\% UI 3.4 to 13.2) in men and 7.0 (95\% UI 2.8 to 18.1 ) in women, indicating a seven times elevated risk of an alcohol-attributable HIV/AIDS death in persons of low SES compared with high SES.

\section{Sensitivity analyses}

The results of both sensitivity analyses are shown in the online supplementary material. Sensitivity analysis I used an asset score that was mapped onto the distribution in the nationally representative data to calculate the HR used to split deaths by SES. This led to increased age-standardised mortality rates for HIV/AIDS mortality attributable to alcohol among men and women of low SES resulting in a mortality rate ratio of 14.3 (95\% UI 5.6 to 37.9$)$ among women and 15.1 (95\% UI 6.8 to 27.7 ) among men. Sensitivity analysis II applied the interaction term between SES and alcohol use exclusively for current alcohol use above the critical thresholds of 61 (men) and $49 \mathrm{~g}$ (women) of pure alcohol per day. This led to lower AAFs for persons of low SES, resulting in a mortality rate ratio of $2.7(95 \%$ UI 0.8 to 7.6$)$ among women and 4.0 (95\% UI 1.4 to 8.3 ) among men.

\section{DISCUSSION}

This study was to our knowledge the first to quantify alcohol-attributable HIV/AIDS mortality burden for different socioeconomic strata. The study showed that age-standardised HIV/AIDS mortality rates attributable to alcohol are much higher for persons of low SES compared with high SES. Based on the vast socioeconomic inequalities between racial groups, the excess burden was to bear predominantly by the black African population. According to our findings, about $10 \%$ to $30 \%$ of HIV/AIDS deaths in persons of low SES could be prevented when (heavy) alcohol use would be prevented. Among persons of high SES, the estimated proportion of deaths that would have been prevented was about $3 \%$ to $9 \%$.

A number of factors contributed to the findings including the higher average alcohol use in grams per day among current drinkers of low SES, the interaction expressing a higher increase in the risk for alcohol users of low $\mathrm{SES}^{10}$ as well as the higher overall risk of dying from HIV/AIDS at low SES. ${ }^{3}$ The findings on drinking patterns by SES were in line with other research from South Africa including the most recent demographic and health survey. ${ }^{67}$ Regarding alcohol use as a contributor to socioeconomic differences in mortality, the findings match those of a recent study that investigated the contribution of alcohol use to socioeconomic differences in self-reported diagnoses in South Africa, concluding that alcohol use accounted for about a quarter of the socioeconomic inequalities in self-reported health. ${ }^{48}$

Overall, the findings of the current study suggest that alcohol use contributes to socioeconomic differences above and beyond socioeconomic differences in drinking patterns. Factors such as malnutrition, contextual and behavioural factors ${ }^{219}$ should be considered as potential contributors to interaction effects between alcohol use 
and SES to increase the HIV infection risk for persons of low SES in future research. Studies from Sub-Saharan Africa support the relevance of the above factors in the associations between HIV/AIDS and sexual risk taking under the influence of alcohol, particularly in a low SES context. ${ }^{50-52}$ However, a systematic analysis of the underlying causal pathways is missing as of now.

\section{Limitations}

In two regards, the national representativeness of the individual data used in the analyses was limited. With respect to data on exposure to alcohol, the SABSSM sampling frame excluded institutionalised and homeless populations, whereby alcohol use of these potentially low SES populations was not accounted for. Furthermore, to this date, there are no nationally representative mortality statistics on HIV/AIDS mortality and SES for South Africa. In the latest release on vital statistics from Statistics South Africa, education and occupation were unknown or not specified for $50 \%$ and $70 \%$ of the deaths, respectively. ${ }^{53}$ Consequently, SES-specific death counts had to be estimated using the relative risk of dying for people with low compared with high SES. A systematic literature review identified no nationally representative cohort studies on cause-specific mortality. ${ }^{3}$ However, the current study included estimates of relative risk from both major South African cohort studies on mortality from Umkhanyakude ${ }^{54}$ and Agincourt. ${ }^{55}$ The overall lower SES of the populations in both cohorts could have led to an underestimation of the socioeconomic differences in HIV/AIDS mortality. Sensitivity analysis I using a mapped asset score indicated that the mortality gap might be much larger than assumed based on the simple median split without mapping.

The division of the total population in two halves was rather crude. However, given the available data and relative risks, the categorisation was chosen to achieve stable and consistent estimates. Furthermore, the representation of the whole of the population was preferred over an extreme group comparison.

A recent study investigating the coverage (ie, the proportion of the total alcohol consumed per capita that gets reported in representative surveys) of five nationally representative South African surveys (including SABSSM) found coverage below $20 \%$ in all of the surveys investigated..$^{35}$ The authors concluded that an over-reporting of abstinence from alcohol could have caused the low coverage additional to reporting lower quantities of alcohol consumed. The triangulation technique used to estimate the 'true' consumption among current drinkers relies on the accuracy of the reported proportion of current abstainers. It is possible that the prevalence of current alcohol use was underestimated based on the survey data, while the average grams per day among current drinkers and thereby the respective AAF were overestimated in the current study.

To this day, it is the common practice in comparative risk assessments to use identical relative risks across countries. ${ }^{567}$ As the required data are often not available for the specific country under investigation, the risk relations are mostly derived from pooled cohort studies or meta-analyses. However, this practice might introduce bias as the same relative risks might not apply to all countries, especially if the underlying causal pathways are not mainly biological. In the present study, the OR relating alcohol use to HIV/AIDS was based on a meta-analysis of experimental studies that were to the large part performed in high-income countries. ${ }^{17}$ However, all other model inputs were based on recent data from South Africa, specifically.

\section{Possible implications for policies and interventions}

Targeting interventions on high-risk groups such as 35 to 54-year-old male current drinkers of low SES could be a potentially cost-effective strategy to reduce the HIV/AIDS burden in South Africa. Interventions addressing alcohol-attributable HIV/AIDS burden should target contextual and behavioural factors associated with alcohol use and the drinking environment of persons of low SES instead of only addressing alcohol use directly. Such factors include malnutrition which is likely to increase the infection risk under the influence of alcohol by exacerbating the immune suppressive effects of alcohol, as well as availability of condoms at drinking venues or alternatives for leisure activities besides drinking venues in low SES housing areas. ${ }^{5-60}$ Of course, improving the wealth inequality between strata in South Africa by reducing poverty would also contribute to an improved situation, but such general measures seem to be more elusive than more concrete actions.

\section{CONCLUSION}

Overall, the study proposed and carried out a methodology to quantify socioeconomic differences in alcohol-attributable mortality, specifically for HIV/AIDS which can be adapted for other contexts. The metrics and data included were based almost exclusively on the most up-to-date data from large, original studies from South Africa-in most cases from the year 2012. High consistency was ensured by using the same measurements of alcohol use, SES and age groups throughout the calculations. The uncertainty around all reported estimations was assessed, reflecting the uncertainty in all metrics that went into the calculation. Despite limitations with regard to the assessment of exposure and the quantification of deaths in each SES group irrespective of alcohol use, the reported estimates are the most adequate given the available data. The study showed that alcohol use contributed to the socioeconomic differences in HIV/AIDS mortality with an about sevenfold mortality rate among persons of low SES compared with high SES in South Africa in 2012. As alcohol-attributable burden is in theory fully preventable, research and policy-makers should work together to address the high burden of alcohol-attributable HIV/AIDS mortality in persons of low SES in South Africa. 
Author affiliations

${ }^{1}$ Institute for Mental Health Policy Research, Centre for Addiction and Mental Health, Toronto, Canada

${ }^{2}$ Institute of Clinical Psychology and Psychotherapy and Center of Clinical Epidemiology and Longitudinal Studies (CELOS), Technische Universität Dresden, Dresden, Germany

${ }^{3}$ Alcohol, Tobacco and Other Drug Research Unit, South African Medical Research Council, Cape Town, South Africa

${ }^{4}$ Department of Psychiatry, University of Stellenbosch, Cape Town, South Africa

${ }^{5}$ Addiction Policy, Dalla Lana School of Public Health, University of Toronto, Toronto, Canada

${ }^{6}$ Faculty of Medicine, Institute of Medical Science, University of Toronto, Toronto, Canada

${ }^{7}$ Department of Psychiatry, University of Toronto, Toronto, Canada

Acknowledgements We kindly thank Dr Houle for providing us with a recalculated relative risk ratio. This work used data of the South African National HIV Prevalence, Incidence, Behaviour and Communication survey 2012 which was funded by the United States President's Emergency Plan for AIDS Relief (PEPFAR), Bill and Melinda Gates Foundation (BMGF), South African National AIDS Council (SANAC) and United Nations Children's Fund (UNICEF). We would like to thank the HSRC's research staff (including data collectors and community outreach staff) and its research partners, namely, the South African Medical Research Council, the Centre for AIDS Development Research and Evaluation (CADRE) and the Centre for Communicable Diseases (CDC). We also would like to thank the communities in which the two surveys were conducted and families who participated in the surveys. Finally, we kindly thank the Africa Centre for Health and Population Studies for providing us with original data and advice on the latter. CP was supported by the Centre for Addiction and Mental Health and the German Academic Scholarship Foundation.

Contributors CP had the overall responsibility of all steps, performed the statistical analyses and wrote the first draft. JR and CDHP supervised the whole working process and added specific knowledge on comparative risk assessments for alcohol use and on the literature about alcohol use and HIV in the South African context. JR contributed to the conceptualisation and to the methodology of the modelling process and the statistical analysis. All authors refined various drafts of the manuscript and approved of the final version.

Funding This research received no specific grant from any funding agency in the public, commercial or not-for-profit sectors.

Competing interests None declared.

Patient consent Not required.

Provenance and peer review Not commissioned; externally peer reviewed.

Data sharing statement No additional data available.

Open Access This is an Open Access article distributed in accordance with the Creative Commons Attribution Non Commercial (CC BY-NC 4.0) license, which permits others to distribute, remix, adapt, build upon this work non-commercially, and license their derivative works on different terms, provided the original work is properly cited and the use is non-commercial. See: http://creativecommons.org/ licenses/by-nc/4.0/

(c) Article author(s) (or their employer(s) unless otherwise stated in the text of the article) 2018. All rights reserved. No commercial use is permitted unless otherwise expressly granted.

\section{REFERENCES}

1. Naghavi M, Abajobir AA, Abbafati $C$, et al. Global, regional, and national age-sex specific mortality for 264 causes of death, 19802016: a systematic analysis for the Global Burden of Disease Study 2016. Lancet 2017;390:1151-210.

2. Wabiri N, Taffa N. Socio-economic inequality and HIV in South Africa. BMC Public Health 2013;13:1037.

3. Probst C, Parry CD, Rehm J. Socio-economic differences in HIV/ AIDS mortality in South Africa. Trop Med Int Health 2016;21:846-55.

4. World Bank Development Research Group. World Development Indicators. Washington, DC: The World Bank Group, 2017;23:2017. http://databank. worldbank.org/data/reports.aspx?source=worlddevelopment-indicatorsAugust

5. Leibbrandt M, Finn A, Woolard I. Describing and decomposing post-apartheid income inequality in South Africa. Dev South Afr 2012;29:19-34.
6. Peltzer K, Davids A, Njuho P. Alcohol use and problem drinking in South Africa: findings from a national population-based survey. Afr J Psychiatry 2011;14:30-7.

7. Parry CD. South Africa: alcohol today. Addiction 2005;100:426-9.

8. Giskes K, Turrell G, Bentley R, et al. Individual and householdlevel socioeconomic position is associated with harmful alcohol consumption behaviours among adults. Aust N Z J Public Health 2011;35:270-7.

9. Bloomfield K, Grittner U, Kramer S, et al. Social inequalities in alcohol consumption and alcohol-related problems in the study countries of the EU concerted action 'gender, culture and alcohol problems: a multi-national study'. Alcohol Alcohol Suppl 2006;41:i26-36.

10. Probst C, Simbayi LC, Parry CDH, et al. Alcohol use, socioeconomic status and risk of HIV infections. AIDS Behav 2017;21:1926-37.

11. Begleiter H, Platz A. The Effects of Alcohol on the Central Nervous System in Humans. In: Kissin B, Begleiter H, eds. The Biology of Alcoholism: physiology and behavior. Boston, MA: Springer US, 1972;2:293-343.

12. Fisher JC, Bang H, Kapiga SH. The association between HIV infection and alcohol use: a systematic review and meta-analysis of African studies. Sex Transm Dis 2007;34:856-63.

13. Baliunas D, Rehm J, Irving $\mathrm{H}$, et al. Alcohol consumption and risk of incident human immunodeficiency virus infection: a meta-analysis. Int J Public Health 2010;55:159-66.

14. Kiwanuka N, Ssetaala A, Ssekandi I, et al. Population attributable fraction of incident HIV infections associated with alcohol consumption in fishing communities around Lake Victoria, Uganda. PLoS One 2017;12:e0171200.

15. Shuper PA, Neuman M, Kanteres F, et al. Causal considerations on alcohol and HIV/AIDS: a systematic review. Alcohol Alcohol 2010;45:159-66.

16. Williams EC, Hahn JA, Saitz R, et al. Alcohol use and human immunodeficiency virus (HIV) infection: current knowledge, implications, and future directions. Alcohol Clin Exp Res 2016;40:2056-72.

17. Scott-Sheldon LA, Carey KB, Cunningham K, et al. Alcohol use predicts sexual decision-making: a systematic review and metaanalysis of the experimental literature. AIDS Behav 2016;20:19-39.

18. Rehm J, Probst C, Shield KD, et al. Does alcohol use have a causal effect on HIV incidence and disease progression? A review of the literature and a modeling strategy for quantifying the effect. Popul Health Metr 2017;15:4.

19. Dunkle KL, Jewkes R, Nduna M, et al. Transactional sex with casual and main partners among young South African men in the rural Eastern Cape: prevalence, predictors, and associations with genderbased violence. Soc Sci Med 2007;65:1235-48.

20. Dunkle KL, Jewkes RK, Brown HC, et al. Transactional sex among women in Soweto, South Africa: prevalence, risk factors and association with HIV infection. Soc Sci Med 2004;59:1581-92.

21. Magni S, Christofides N, Johnson S, et al. Alcohol use and transactional sex among women in South Africa: results from a Nationally Representative Survey. PLoS One 2015;10:e0145326.

22. Townsend L, Ragnarsson A, Mathews C, et al. "Taking care of business": alcohol as currency in transactional sexual relationships among players in Cape Town, South Africa. Qual Health Res 2011;21:41-50.

23. Sirotin N, Hoover D, Segal-Isaacson CJ, et al. Structural determinants of food insufficiency, low dietary diversity and BMI: a cross-sectional study of HIV-infected and HIV-negative Rwandan women. BMJ Open 2012;2:e000714.

24. Steyn NP, Walker AR. Nutritional status and food security in Sub-Saharan Africa: predictions for 2020. Asia Pac J Clin Nutr 2000;9:1-6.

25. Neuman MG, Schneider M, Nanau RM, et al. Alcohol consumption, progression of disease and other comorbidities, and responses to antiretroviral medication in people living with HIV. AIDS Res Treat 2012;2012:1-14.

26. Azar MM, Springer SA, Meyer JP, et al. A systematic review of the impact of alcohol use disorders on HIV treatment outcomes, adherence to antiretroviral therapy and health care utilization. Drug Alcohol Depend 2010;112:178-93.

27. Probst C, Roerecke M, Behrendt S, et al. Socioeconomic differences in alcohol-attributable mortality compared with all-cause mortality: a systematic review and meta-analysis. Int $\mathrm{J}$ Epidemiol 2014;43:1314-27.

28. Marmot M. Social determinants of health inequalities. Lancet 2005;365:1099-104.

29. Murray CJ, Lopez AD, Jamison DT. The global burden of disease in 1990: summary results, sensitivity analysis and future directions. Bull World Health Organ 1994;72:495-509. 
30. Bank W. World Development Report 1993: Investing in Health. New York: Oxford University Press, 1993.

31. Murray CJL, López AD. eds. The global burden of disease: a comprehensive assessment of mortality and disability from diseases, injuries, and risk factors in 1990 and projected to 2020. Cambridge: Harvard School of Public Health on behalf of the World Health Organization and the World Bank, 1996.

32. Ahmad OB, Boschi-Pinto C, Lopez AD, et al. Age standardization of rates: a new WHO standard. Geneva: World Health Organization, 2001.

33. Shisana O, Rehle T, Simbayi LC, et al. South African National HIV Prevalence, Incidence and Behaviour Survey, 2012. Cape Town, South Africa: HSRC Press 2014.

34. Gmel G, Rehm J. Measuring alcohol consumption. Contemp Drug Probl 2004;31:467-540.

35. Probst C, Shuper PA, Rehm J. Coverage of alcohol consumption by national surveys in South Africa. Addiction 2017;112:705-10.

36. Kehoe T, Gmel G, Shield KD, et al. Determining the best populationlevel alcohol consumption model and its impact on estimates of alcohol-attributable harms. Popul Health Metr 2012;10:6.

37. Rehm J, Kehoe T, Gmel G, et al. Statistical modeling of volume of alcohol exposure for epidemiological studies of population health: the US example. Popul Health Metr 2010;8:3.

38. World Health Organization. Global Information System on Alcohol and Health Geneva. Switzerland: World Health Organization, 2017;2016:10. http://apps.who.int/gho/data/node.main.GISAHMarch.

39. Zablotska IB, Gray RH, Serwadda D, et al. Alcohol use before sex and HIV acquisition: a longitudinal study in Rakai, Uganda. AIDS 2006:20:1191-6.

40. Houle B, Clark SJ, Gómez-Olivé FX, et al. The unfolding countertransition in rural South Africa: mortality and cause of death, 19942009. PLoS One 2014;9:e100420.

41. Welaga P, Hosegood V, Weiner R, et al. Coming home to die? The association between migration and mortality in rural South Africa. BMC Public Health 2009;9:193.

42. Nyirenda M, Hosegood V, Bärnighausen T, et al. Mortality levels and trends by HIV serostatus in rural South Africa. AIDS 2007;21:S73-9.

43. INDEPTH Network. INDEPTH Standardized Verbal Autopsy questionnaire. Revised, 2003.

44. Statistics South Africa. Census 2011 statistical release (Revised): P0301.4. Pretoria: Statistics South Africa, 2012.

45. Josse J, Husson F. missMDA: a package for handling missing values in multivariate data analysis. J Stat Softw 2016;70:1-31.

46. Gmel G, Shield KD, Frick $\mathrm{H}$, et al. Estimating uncertainty of alcoholattributable fractions for infectious and chronic diseases. BMC Med Res Methodol 2011;11:48.
47. National Department of Health, Statistics South Africa, South African Medical Research Council, et al. South Africa Demographic and Health Survey 2016: Keylndicator Report. Pretoria, South Africa: $\mathrm{NDoH}$, Stats SA, SAMRC, and ICF, 2017.

48. Mukong AK, Van Walbeek $\mathrm{C}$, Ross $\mathrm{H}$. Lifestyle and income-related inequality in health in South Africa. Int J Equity Health 2017;16:103.

49. Schaible UE, Kaufmann SH. Malnutrition and infection: complex mechanisms and global impacts. PLoS Med 2007;4:e115.

50. Roth EA, Benoit C, Jansson M, et al. Public drinking venues as risk environments: Commercial sex, alcohol and violence in a large informal settlement in Nairobi, Kenya. Hum Ecol 2017;45:277-83.

51. Eaton LA, Cain DN, Pitpitan EV, et al. Exploring the relationships among food insecurity, alcohol use, and sexual risk taking among men and women living in South African townships. $J$ Prim Prev 2014:35:255-65.

52. Eaton LA, Kalichman SC, Pitpitan EV, et al. The relationship between attending alcohol serving venues nearby versus distant to one's residence and sexual risk taking in a South African township. $J$ Behav Med 2014;37:381-90

53. Statistics South Africa. Statistical Release P0309.3 - Mortality and causes of death in South Africa, 2015: Findings from death notification. Pretoria, South Africa: Statistics South Africa, 2017.

54. Tanser F, Hosegood V, Bärnighausen T, et al. Cohort profile: Africa Centre Demographic Information System (ACDIS) and populationbased HIV survey. Int J Epidemiol 2008;37:956-62.

55. Kahn K, Collinson MA, Gómez-Olivé FX, et al. Profile: Agincourt health and socio-demographic surveillance system. Int J Epidemiol 2012;41:988-1001.

56. Gakidou E, Afshin A, Abajobir AA, et al. Global, regional, and national comparative risk assessment of 84 behavioural, environmental and occupational, and metabolic risks or clusters of risks, 1990-2016: a systematic analysis for the Global Burden of Disease Study 2016. Lancet 2017;390:1345-422.

57. World Health Organization. Global status report on alcohol and health. Geneva, Switzerland: World Health Organization, 2014.

58. Pitpitan EV, Kalichman SC. Reducing HIV risks in the places where people drink: prevention interventions in alcohol venues. AIDS Behav 2016;20:119-33.

59. Weybright EH, Caldwell LL, Ram N, et al. The dynamic association between healthy leisure and substance use in South African adolescents: a state and trait perspective. World Leis $J$ 2014:56:99-109.

60. Motamedi M, Caldwell L, Wegner L, et al. Girls just want to know where to have fun: preventing substance use initiation in an underresourced community in South Africa through healthwise. Prev Sci 2016;17:700-9. 